Bull. Mater. Sci., Vol. 23, No. 4, August 2000, pp. 335-340. (C) Indian Academy of Sciences.

\title{
Electrical conductivity measurements on gel grown KDP crystals added with some ammonium compounds
}

\author{
T H FREEDA and C MAHADEVAN* \\ Department of Physics, S.T. Hindu College, Nagercoil 629 002, India
}

MS received 20 August 1999; revised 19 May 2000

\begin{abstract}
Pure and impurity added [with $\mathrm{NH}_{4} \mathrm{Cl}, \mathrm{NH}_{4} \mathrm{NO}_{3}, \mathrm{NH}_{4} \mathrm{H}_{2} \mathrm{PO}_{4},\left(\mathrm{NH}_{4}\right)_{2} \mathrm{CO}_{3}$ and $\left(\mathrm{NH}_{4}\right)_{2} \mathrm{SO}_{4}$ ] $\mathrm{KDP}_{\text {sin- }}$ gle crystals were grown by the gel method using silica gels. Electrical conductivity measurements were carried out along both the unique axis and perpendicular directions at various temperatures ranging from 28 to $140^{\circ} \mathrm{C}$ by the conventional two-probe method. The present study shows that the conductivity in KDP crystals, for all the five dopants considered, increases with the increase in impurity concentration and temperature. Activation energies were also determined and reported.
\end{abstract}

Keywords. Impurity added KDP crystals; gel method; electrical conductivity; activation energy.

\section{Introduction}

Potassium dihydrogen orthophosphate, $\mathrm{KH}_{2} \mathrm{PO}_{4}$ (abbreviated as KDP) crystals have created considerable interest among several research workers. Pure and impurity added KDP crystals were grown from aqueous solutions and also in gel media by different workers (Varma et al 1983; Henisch 1988; Rashkovich 1991; Udupa et al 1997). KDP belongs to the scalenohedral (twelve sided polyhedron) class of tetragonal crystal system. It has a tetramolecular unit cell having the dimensions (Wyckoff 1960) given as $a=b=7.448 \AA$ and $c=6.977 \AA$. KDP is ferroelectric well below room temperature and the curie temperature $T$ is $123 \mathrm{~K}$ (Subbarao 1973). KDP is soluble in water and the molecular weight is 136.09 (Dean 1979).

In KDP type of crystals the possible type of point defects which help the electrical conduction process are the ionization defects, viz. $\left(\mathrm{HPO}_{4}\right)^{2-}$ and $\mathrm{H}_{3} \mathrm{PO}_{4}$ produced as a result of proton jump from one phosphate group to another along the same bond (George 1989). The electrical conduction in KDP crystals has been established to be protonic (Keeffe and Perrino 1967; Shanmugham et al 1982). The conductivity value of KDP crystals increased when added with oxalate (crystals grown by the gel method) (Shanmugham et al 1985) and chloride (crystals grown by the slow evaporation method) (Ramasubramanian and Mahadevan 1991) impurities. This was explained by considering the replacement of $\left(\mathrm{H}_{2} \mathrm{PO}_{4}\right)^{-1}$ ions by $\left(\mathrm{C}_{2} \mathrm{O}_{4}\right)^{-2}$ and $\mathrm{Cl}^{-1}$ ions. It was also found that the activation energy values for KDP crystals do not vary much when added with oxalate impurity of various concentrations (Shanmugham et al 1985). It has been observed (Udupa et al 1997) that the KDP system has become complex after ion

*Author for correspondence irradiation and it shows irregular behaviour with regard to conductivity property.

At any particular temperature, the Gibb's free energy of a crystal is minimum when a certain fraction of ions leave the normal lattice. As the temperature rises, more and more defects are produced which, in turn, increases the conductivity (Jain and Dahake 1964). In the high temperature (intrinsic) region, the effect of impurity on electrical conduction will not change appreciably whereas in the low temperature (extrinsic) region, the presence of impurity in the crystal increases its conductivity. The electrical conduction in dielectrics is mainly a defect controlled process in the low temperature region. The presence of impurities and vacancies mainly determine this region. The energy needed to form the defect is much larger than the energy needed for its drift (Shanmugham et al 1985; Udupa et al 1997). The conductivity of the crystal in the higher temperature region is determined by the intrinsic defects caused by the thermal fluctuations in the crystal.

We have, in the present work attempted to study the effect of ionic impurities [ammonium compounds with and without the common ion $\left(\mathrm{H}_{2} \mathrm{PO}_{4}\right)^{-1}$ added heavily (impurity added in the KDP solution used for the growth of crystals with impurity concentration ranging from 2000 to $10000 \mathrm{ppm}$, i.e. 0.2 to 1.0 mole $\%)$ ] on the electrical conductivity at various temperatures ranging from 28 (room temperature) to $140^{\circ} \mathrm{C}$ of $\mathrm{KDP}$ crystals grown by the gel method. A report of our work is presented and discussed.

\section{Experimental}

KDP crystals were grown in silica gels prepared from sodium metasilicate (SMS) by the reduction of solubility 
method. Analytical reagent (AR) grade samples of KDP, ammonium chloride $\left[\mathrm{NH}_{4} \mathrm{Cl}\right]$, ammonium nitrate $\left[\mathrm{NH}_{4} \mathrm{NO}_{3}\right]$, ammonium dihydrogen orthophosphate $\left[\mathrm{NH}_{4} \mathrm{H}_{2} \mathrm{PO}_{4}\right]$, ammonium carbonate $\left[\left(\mathrm{NH}_{4}\right)_{2} \mathrm{CO}_{3}\right]$ and ammonium sulphate $\left[\left(\mathrm{NH}_{4}\right)_{2} \mathrm{SO}_{4}\right]$ along with double distilled water and ethyl alcohol were used.

KDP was added with $\mathrm{NH}_{4} \mathrm{Cl}, \mathrm{NH}_{4} \mathrm{NO}_{3}, \mathrm{NH}_{4} \mathrm{H}_{2} \mathrm{PO}_{4}$, $\left(\mathrm{NH}_{4}\right)_{2} \mathrm{CO}_{3}$ and $\left(\mathrm{NH}_{4}\right)_{2} \mathrm{SO}_{4}$ separately each in six different KDP : impurity molecular ratios, viz. $1: 0.000$ (pure KDP), $1: 0 \cdot 002,1: 0 \cdot 004,1: 0 \cdot 006,1: 0 \cdot 008$ and $1: 0 \cdot 010$. The impurity was dissolved in $2.5 \mathrm{M}$ solution of KDP.

SMS solution of density $1.08 \mathrm{~g} / \mathrm{cc}$ was added to $2.5 \mathrm{M}$ KDP solution in the volume ratio $1: 4$ (SMS : KDP). Thus prepared gel solution was then transferred to test tubes (of diameter $2.5 \mathrm{~cm})(20 \mathrm{ml}$ in each tube) and was allowed to set at room temperature. Gelation occurred in about $15 \mathrm{~h}$. Then it was kept as such for one day for gel ageing. After that an equal volume of ethyl alcohol was added slowly above the gel and the test tubes were tightly closed with rubber corks to prevent evaporation of alcohol. Alcohol reduces the solubility of KDP which first precipitate at the gel alcohol interface. Diffusion of alcohol into the gel was followed by formation of nuclei which then grew larger. Completion of crystallization took about 15 to 20 days.

Scalenohedral morphology was exhibited by all the crystals grown. Crystals with high transparency and large defect-free size $(>3 \mathrm{~mm})$ were selected and used for the electrical conductivity measurements. The extended portions of the crystals were removed completely and the opposite faces were polished and coated with good quality graphite to obtain a good ohmic contact.

The conductivity measurements were carried out along both the unique axis $(c-)$ and perpendicular ( $a$ - and $b$-) directions for all the twentysix crystals grown using the conventional two-probe technique at various temperatures ranging from 28 to $140^{\circ} \mathrm{C}$. The resistance of the crystals were measured using a thousand megohmmeter. The observations were made while cooling the sample. The dimensions of the crystals were measured using a travelling microscope $($ L.C. $=0.001 \mathrm{~cm})$. The conductivity $(\sigma)$ of the crystal was calculated using the relation

$$
\sigma=\frac{d}{R A}
$$

where $R$ is the measured resistance, $d$ the thickness of the sample and $A$ the area of the face in contact with the electrode. The $\sigma$ values were fitted into the equation

$$
\sigma T=\sigma_{0} \exp (-E / k T)
$$

and the activation energy $(E)$ values were calculated. Here $k$ is the Boltzmann's constant, $T$ the absolute temperature and $\sigma_{0}$ a constant depending on the material.

When the crystals are grown in gel media, there is a possibility that the conductivity and related properties are different for different crystals even though they are grown in the same container. It would be better if there is a possibility to estimate quantitatively the concentration level of the impurity that is present in each crystal. But, it is very difficult to do so since the impurities considered in the present study are ammonium compounds without any metal atom. Hence, in order to understand qualitatively (atleast) whether the added impurity has entered into the KDP lattice or not, we carried out the density measurement by using the floatation technique.

\section{Results and discussion}

It was observed that the difference in densities of crystals grown in the same container was very small and negligible. Average densities are given in table 1 . The value observed for pure KDP $(2.344 \mathrm{~g} / \mathrm{cc})$ compares well with that reported in the literature $(2.338 \mathrm{~g} / \mathrm{cc})$ (Dean 1979). For all the five impurities considered in the present study, the observed decrease of density of KDP crystal caused by the impurities indicates that the impurities have entered into the lattice of KDP crystals. Moreover, it can be seen that the density decreases further with the increase in impurity concentration of the aqueous solution of KDP used for the growth of crystals.

The $\sigma$ values obtained along the two directions ( $a$ - and $b$-) perpendicular to the unique axis (c-direction) are, within experimental error, the same. Figures $1-5$ show the plots of $\ln (\sigma T)$ against $1000 / T$ for the pure and impurity added KDP crystals when the field is perpendicular (along the $a$-direction) to the unique axis. Figures 6-10 show the plots when the field is parallel to the unique axis. The values of the activation energy $E$ for pure and impurity added KDP crystals are given in table 1 .

Conductivities obtained in the present study are of the same order with those obtained by previous authors for the KDP crystals $\left(\times 10^{-6} \mathrm{mho} / \mathrm{metre}\right)$ (Harris and Vella

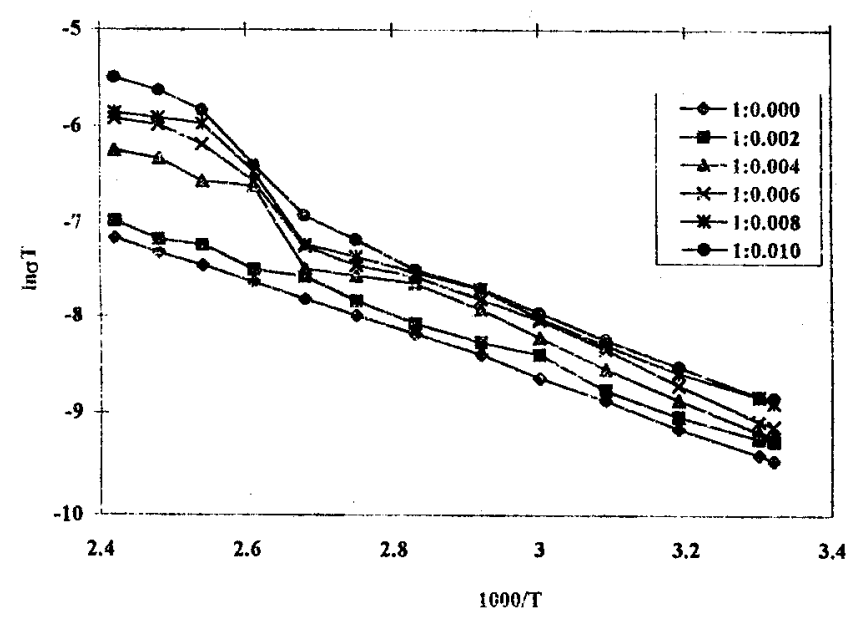

Figure 1. Variation of $\ln \sigma T$ with $1000 / T$ for $\mathrm{NH}_{4} \mathrm{Cl}$ added KDP crystals along $a$-direction. 
1966; Shanmugham et al 1985; Ramasubramanian and Mahadevan 1991; Udupa et al 1997).

It can be seen that, for all the impurities considered in the present study, the electrical conductivity increases with the increase in impurity concentration and temperature. This is similar to that observed for oxalate doped KDP crystal (Shanmugham et al 1985). The defect concentration will increase exponentially with temperature and consequently the electrical conduction also increases. The addition of impurity further increases the electrical conduction in the temperature region considered.

The electrical conduction in KDP crystals has been established (Keeffe and Perrino 1967; Shanmugham et al 1982) to be protonic. In KDP type of crystals the possible type of point defects which help the electrical conduction process are the ionization defects, viz. $\left(\mathrm{HPO}_{4}\right)^{2-}$ and $\left(\mathrm{H}_{3} \mathrm{PO}_{4}\right)$, produced as a result of proton jump from one phosphate group to another along the same bond (George 1989) and L and D defects. The conduction region considered in the present study seems to be connected to mobility of vacancies. The low activation energies observed suggests that oxygen vacancies may be responsible for conduction in this region.

If the probability of occupation of an interstice is $f$, then the probability of finding a vacant neighbour site is $(1-f)$. Even for very high concentrations, of the order of $10^{20} \mathrm{~cm}^{-3}, f$ does not exceed $10^{-2}$ so that in real cases with concentration of interstitials of the order of $10^{15}$ to $10^{20} \mathrm{~cm}^{-3},(1-f) \approx 1$ (Bunget and Popescu 1984).

Jaccard and his co-workers (Granicher et al 1957; Jaccard 1959) have shown that proton conduction may be accounted for by motion of protons accompanied by a $D$ defect (excess of positive charge). Migration of these defects may only modify electric polarization and may not

Table 1. Activation energies and densities of pure and impurity added KDP crystals.

\begin{tabular}{|c|c|c|c|c|}
\hline & \multirow{2}{*}{$\begin{array}{l}\text { System } \\
\text { (impurity in mole\%) }\end{array}$} & \multirow{2}{*}{$\begin{array}{l}\text { Density } \\
(\mathrm{g} / \mathrm{cc})\end{array}$} & \multicolumn{2}{|c|}{ Activation energy, $E(\mathrm{eV})$ along } \\
\hline & & & $a$-direction & $c$-direction \\
\hline (a) & Pure KDP & $2 \cdot 344$ & $0 \cdot 220$ & $0 \cdot 216$ \\
\hline \multirow[t]{2}{*}{ (b) } & $\mathrm{NH}_{4} \mathrm{Cl}$ added $\mathrm{KDP}$ & & & \\
\hline & $\begin{array}{l}0 \cdot 2 \\
0 \cdot 4 \\
0 \cdot 6 \\
0 \cdot 8 \\
1 \cdot 0\end{array}$ & $\begin{array}{l}2 \cdot 341 \\
2 \cdot 332 \\
2 \cdot 309 \\
2 \cdot 249 \\
2 \cdot 178\end{array}$ & $\begin{array}{l}0 \cdot 222 \\
0 \cdot 291 \\
0 \cdot 309 \\
0 \cdot 300 \\
0 \cdot 325\end{array}$ & $\begin{array}{l}0 \cdot 211 \\
0 \cdot 269 \\
0 \cdot 277 \\
0 \cdot 279 \\
0 \cdot 311\end{array}$ \\
\hline \multirow[t]{2}{*}{ (c) } & $\mathrm{NH}_{4} \mathrm{NO}_{3}$ added $\mathrm{KDP}$ & & & \\
\hline & $\begin{array}{l}0 \cdot 2 \\
0 \cdot 4 \\
0 \cdot 6 \\
0 \cdot 8 \\
1 \cdot 0\end{array}$ & $\begin{array}{l}2 \cdot 330 \\
2 \cdot 321 \\
2 \cdot 313 \\
2 \cdot 280 \\
2 \cdot 240\end{array}$ & $\begin{array}{l}0 \cdot 217 \\
0 \cdot 213 \\
0 \cdot 213 \\
0 \cdot 211 \\
0 \cdot 210\end{array}$ & $\begin{array}{l}0 \cdot 233 \\
0 \cdot 242 \\
0 \cdot 242 \\
0 \cdot 267 \\
0 \cdot 266\end{array}$ \\
\hline \multirow[t]{2}{*}{ (d) } & $\mathrm{NH}_{4} \mathrm{H}_{2} \mathrm{PO}_{4}$ added $\mathrm{KDP}$ & & & \\
\hline & $\begin{array}{l}0 \cdot 2 \\
0 \cdot 4 \\
0 \cdot 6 \\
0 \cdot 8 \\
1 \cdot 0\end{array}$ & $\begin{array}{l}2 \cdot 334 \\
2 \cdot 295 \\
2 \cdot 250 \\
2 \cdot 201 \\
2 \cdot 141\end{array}$ & $\begin{array}{l}0 \cdot 222 \\
0 \cdot 220 \\
0 \cdot 223 \\
0 \cdot 222 \\
0 \cdot 222\end{array}$ & $\begin{array}{l}0 \cdot 235 \\
0 \cdot 234 \\
0 \cdot 233 \\
0 \cdot 239 \\
0 \cdot 236\end{array}$ \\
\hline \multirow[t]{2}{*}{ (e) } & $\left(\mathrm{NH}_{4}\right)_{2} \mathrm{CO}_{3}$ added KDP & & & \\
\hline & $\begin{array}{l}0 \cdot 2 \\
0 \cdot 4 \\
0 \cdot 6 \\
0 \cdot 8 \\
1 \cdot 0\end{array}$ & $\begin{array}{l}2 \cdot 333 \\
2 \cdot 324 \\
2 \cdot 315 \\
2 \cdot 294 \\
2 \cdot 259\end{array}$ & $\begin{array}{l}0 \cdot 221 \\
0 \cdot 230 \\
0 \cdot 234 \\
0 \cdot 255 \\
0 \cdot 260\end{array}$ & $\begin{array}{l}0 \cdot 285 \\
0 \cdot 338 \\
0 \cdot 360 \\
0 \cdot 385 \\
0 \cdot 401\end{array}$ \\
\hline \multirow[t]{2}{*}{ (f) } & $\left(\mathrm{NH}_{4}\right)_{2} \mathrm{SO}_{4}$ added $\mathrm{KDP}$ & & & \\
\hline & $\begin{array}{l}0 \cdot 2 \\
0 \cdot 4 \\
0 \cdot 6 \\
0 \cdot 8 \\
1 \cdot 0\end{array}$ & $\begin{array}{l}2 \cdot 339 \\
2 \cdot 331 \\
2 \cdot 322 \\
2 \cdot 299 \\
2 \cdot 246\end{array}$ & $\begin{array}{l}0 \cdot 219 \\
0 \cdot 218 \\
0 \cdot 217 \\
0 \cdot 215 \\
0 \cdot 213\end{array}$ & $\begin{array}{l}0 \cdot 237 \\
0 \cdot 240 \\
0 \cdot 232 \\
0 \cdot 247 \\
0 \cdot 244\end{array}$ \\
\hline
\end{tabular}


change the charge at an electrode (Granicher et al 1957). The motion of defects occurs by some kind of rotation in the bond with defects. The speed of displacement $v=v a$, where $a$ and $v$ are the distance and frequency respectively of the jump from one bond to the other. Utilization of the Nernst-Einstein equation with the diffusion coefficient given by

$$
D=(1 / 2) v a^{2} \exp (-E / k T),
$$

where $a=2 \cdot 8 \AA$, while $E$ equals the activation energy of conduction, has yielded in the case of pure KDP for the jump frequency $3 \times 10^{13} \mathrm{~s}^{-1}$. This value was considered reasonable since it was close to $4 \times 10^{13} \mathrm{~s}^{-1}$, found for oscillation frequencies of the $\mathrm{P}-\mathrm{O}-\mathrm{H}$ group in orthophosphates (Bunget and Popescu 1984).

If the sample crystal is placed in a stationary electric field (as in the present study) the carriers may be considered to be contained in an enclosure bounded by the

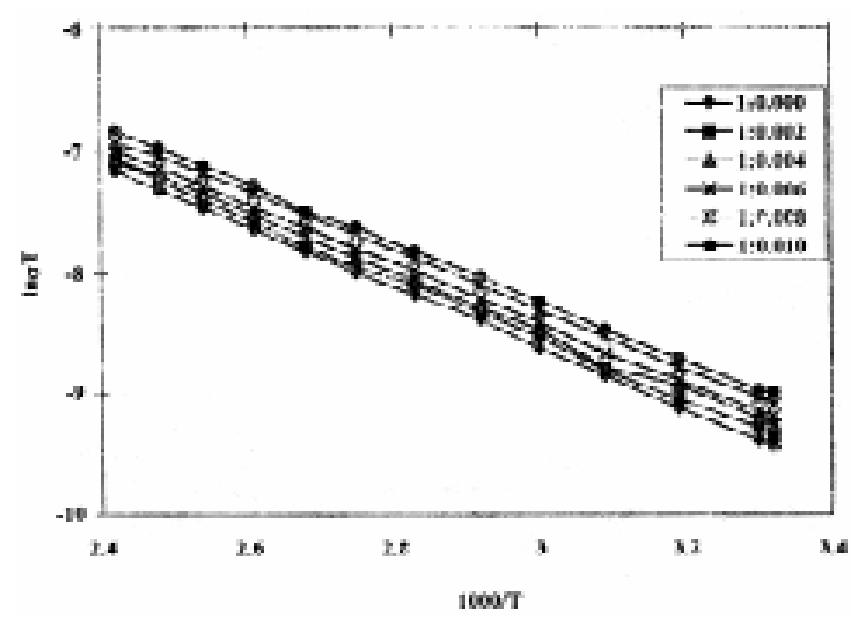

Figure 2. Variation of $\ln \sigma T$ with $1000 / T$ for $\mathrm{NH}_{4} \mathrm{NO}_{3}$ added KDP crystals along $a$-direction.

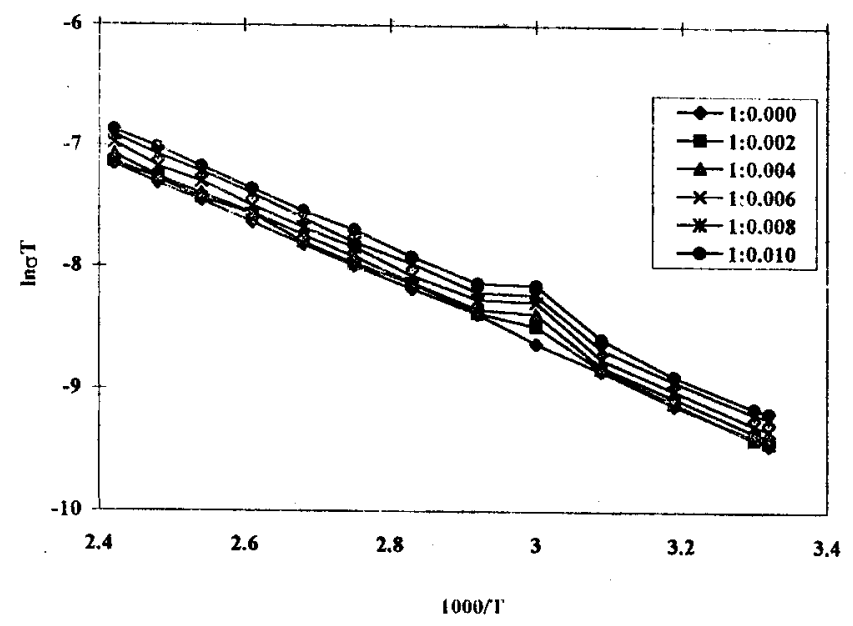

Figure 3. Variation of $\ln \sigma T$ with $1000 / T$ for ADP added KDP crystals along $a$-direction. capacitor plates. As the carriers may not leave the enclosure, they accumulate in the regions close to the plates which causes a concentration gradient to be formed and this gradient feeds a diffusion current. At equilibrium the diffusion current density equals that of the drift current. Charge accumulation is related to inhomogeneities of the material, the agglomeration of impurity ions by diffusion in the vicinity of electrodes or chemical changes in layers close to electrodes (Bunget and Popescu 1984).

The conductivities are more along the $a$-direction than those along the $c$-direction for all the impurities considered in the present study at low temperatures. This is in correspondence with the results obtained by the previous authors for their systems (Harris and Vella 1966; Shanmugham et al 1985). For the impurity $\left(\mathrm{NH}_{4}\right)_{2} \mathrm{CO}_{3}$ (for all the impurity concentrations) the conductivity along $a$ direction becomes less than that along $c$-direction beyond certain temperatures $\left(70^{\circ} \mathrm{C}\right.$ for $0.2 \mathrm{~mole} \%$ and $30^{\circ} \mathrm{C}$ for other concentrations). For the impurity $\left(\mathrm{NH}_{4}\right) \mathrm{NO}_{3}$ the

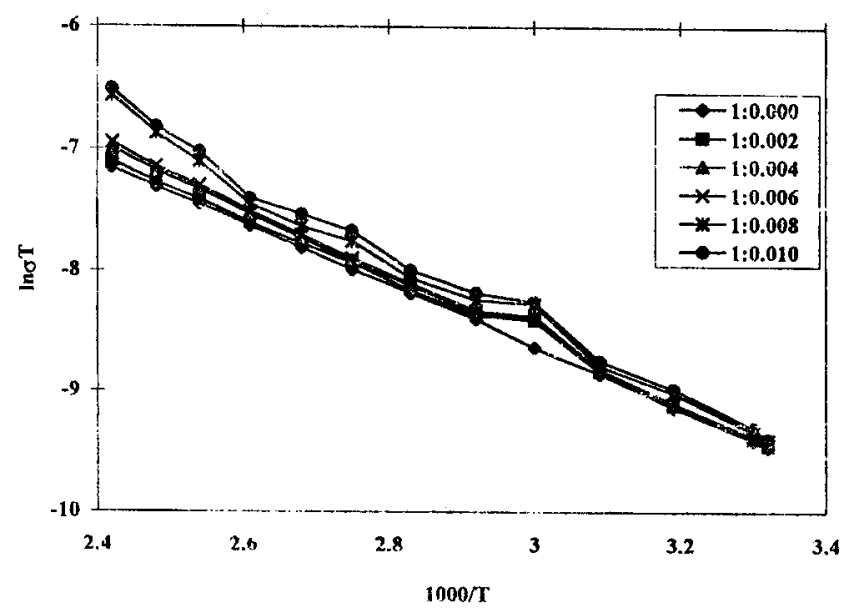

Figure 4. Variation of $\ln \sigma T$ with $1000 / T$ for $\left(\mathrm{NH}_{4}\right)_{2} \mathrm{CO}_{3}$ added KDP crystals along $a$-direction.

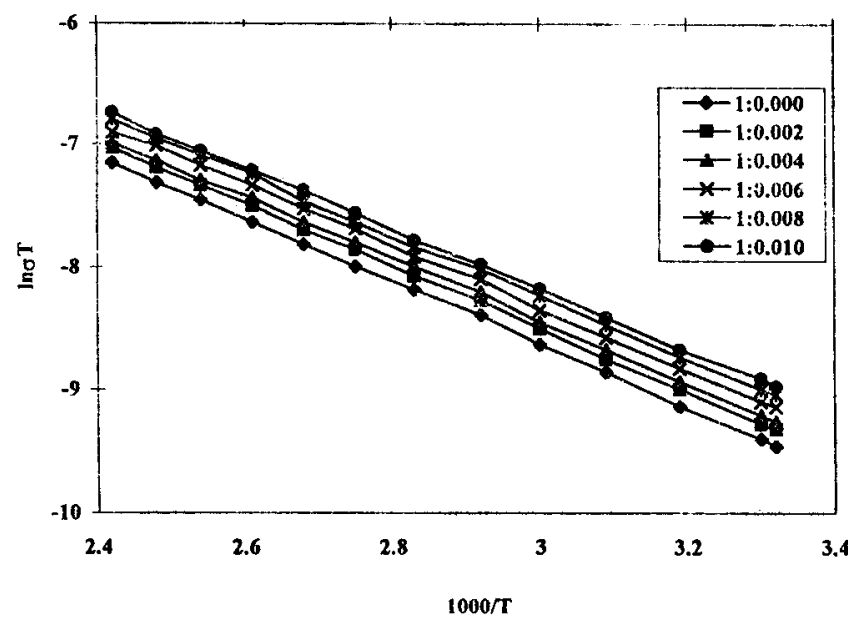

Figure 5. Variation of $\ln \sigma T$ with $1000 / T$ for $\left(\mathrm{NH}_{4}\right)_{2} \mathrm{SO}_{4}$ added KDP crystals along $a$-direction. 
conductivity along $a$-direction becomes less than that along $c$-direction beyond $70^{\circ} \mathrm{C}$ and $60^{\circ} \mathrm{C}$ for 0.8 mole $\%$ and 1.0 mole $\%$ respectively.

At the lowest temperature considered in the present study $\left(28^{\circ} \mathrm{C}\right)$, the conductivities of the pure and impurity added KDP crystals follow a particular order for all the impurity concentrations. However, the order is different for $a$ and $c$-directions. For the $a$-direction, it follows:

$$
\begin{aligned}
\sigma \text { [pure KDP] } & <\sigma\left[\left(\mathrm{NH}_{4}\right)_{2} \mathrm{CO}_{3} \text { added KDP }\right] \\
& <\sigma\left[\mathrm{NH}_{4} \mathrm{H}_{2} \mathrm{PO}_{4} \text { added KDP }\right] \\
& <\sigma\left[\mathrm{NH}_{4} \mathrm{NO}_{3} \text { added KDP }\right] \\
& <\sigma\left[\left(\mathrm{NH}_{4}\right)_{2} \mathrm{SO}_{4} \text { added KDP }\right] \\
& <\sigma\left[\mathrm{NH}_{4} \mathrm{Cl} \text { added KDP }\right] .
\end{aligned}
$$

For the $c$-direction it follows:

$$
\begin{aligned}
\sigma \text { [pure KDP }] & <\sigma\left[\mathrm{NH}_{4} \mathrm{NO}_{3} \text { added KDP }\right] \\
& <\sigma\left[\mathrm{NH}_{4} \mathrm{H}_{2} \mathrm{PO}_{4} \text { added KDP }\right]
\end{aligned}
$$

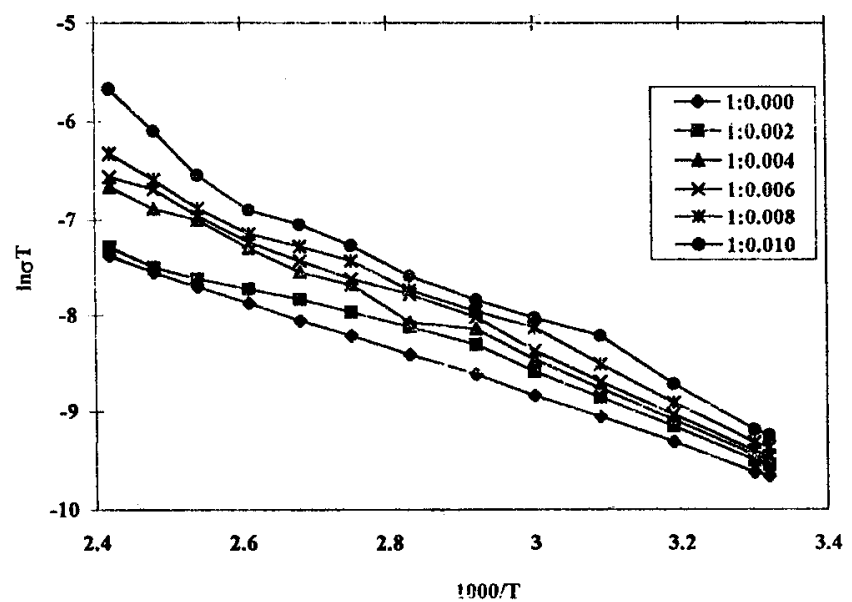

Figure 6. Variation of $\ln \sigma T$ with $1000 / T$ for $\mathrm{NH}_{4} \mathrm{Cl}$ added KDP crystals along $c$-direction.

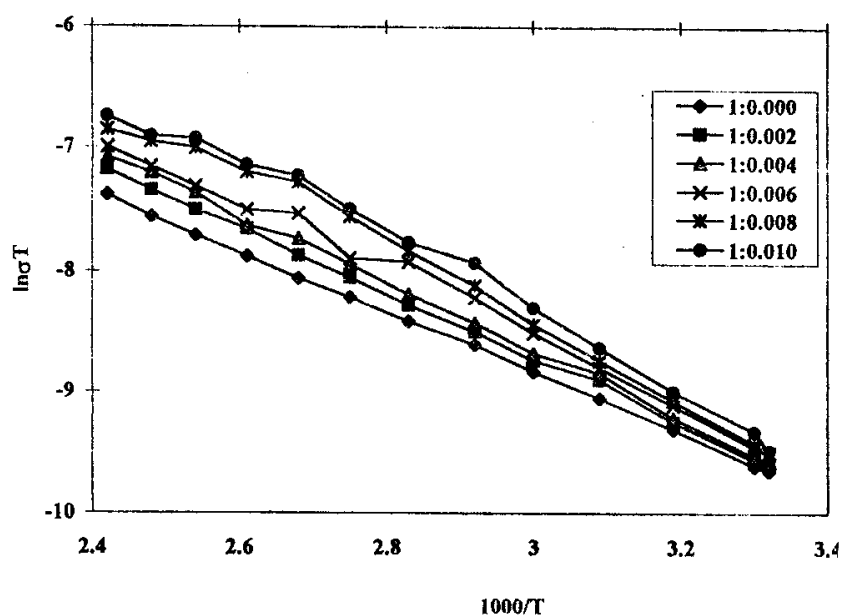

Figure 7. Variation of $\ln \sigma T$ with $1000 / T$ for $\mathrm{NH}_{4} \mathrm{NO}_{3}$ added KDP crystals along $c$-direction.
$<\sigma\left[\left(\mathrm{NH}_{4}\right)_{2} \mathrm{SO}_{4}\right.$ added KDP $]$

$<\sigma\left[\left(\mathrm{NH}_{4}\right)_{2} \mathrm{CO}_{3}\right.$ added KDP $]$

$<\sigma\left[\mathrm{NH}_{4} \mathrm{Cl}\right.$ added KDP $]$.

At the highest temperature considered in the present study $\left(140^{\circ} \mathrm{C}\right)$, the conductivities observed for the impurity added KDP crystals along the $c$-direction are minimum for the $\mathrm{NH}_{4} \mathrm{H}_{2} \mathrm{PO}_{4}$ added KDP and maximum for the $\left(\mathrm{NH}_{4}\right)_{2} \mathrm{CO}_{3}$ added KDP for all the impurity concentrations considered. However, no systematic order is observed with that along the $a$-direction.

Though it is not possible to make an authentic statement with the observations made in the present study, it may be stated that while the $\mathrm{NH}_{4} \mathrm{Cl}$ impurity is able to create more defects the $\mathrm{NH}_{4} \mathrm{H}_{2} \mathrm{PO}_{4}$ impurity is able to create less defects among the impurities considered in the present study. Hence, the present study gives further evidence to the statement (Keeffe and Perrino 1967;

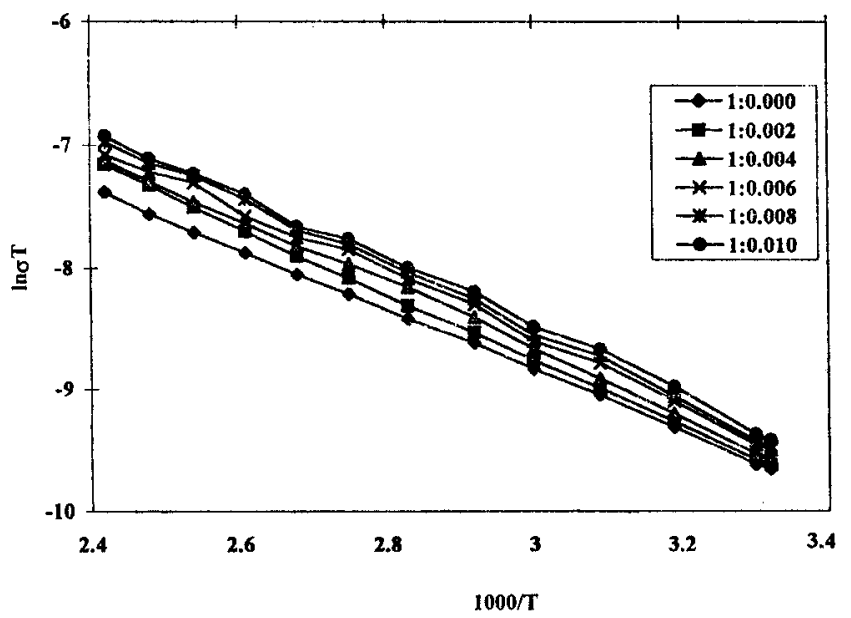

Figure 8. Variation of $\ln \sigma T$ with $1000 / T$ for ADP added KDP crystals along $c$-direction.

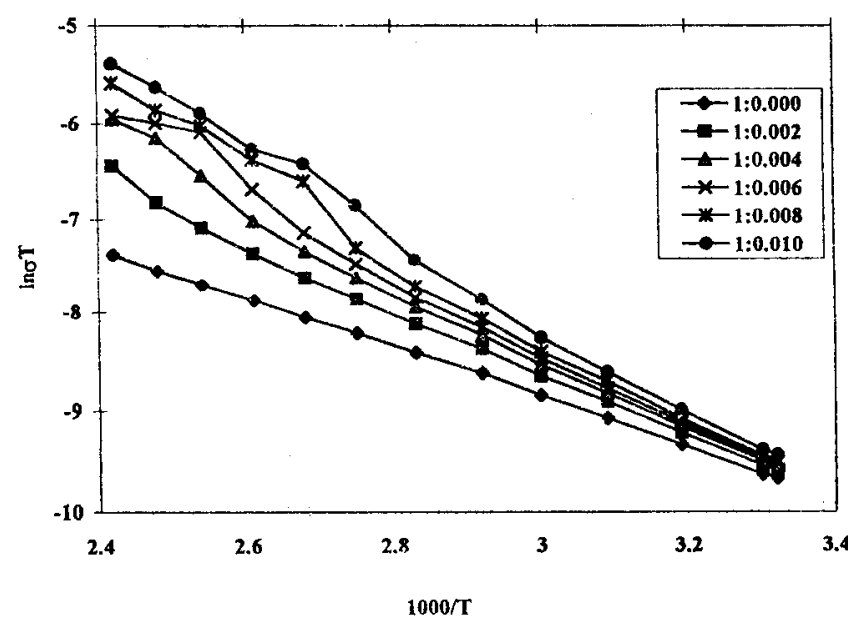

Figure 9. Variation of $\ln \sigma T$ with $1000 / T$ for $\left(\mathrm{NH}_{4}\right)_{2} \mathrm{CO}_{3}$ added KDP crystals along $c$-direction. 


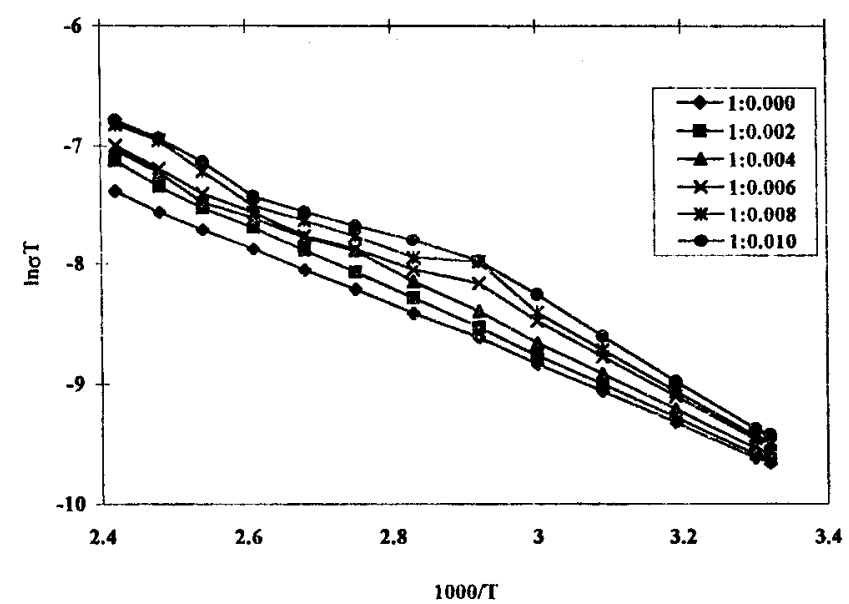

Figure 10. Variation of $\ln \sigma T$ with $1000 / T$ for $\left(\mathrm{NH}_{4}\right)_{2} \mathrm{SO}_{4}$ added KDP crystals along $c$-direction.

Shanmugham et al 1982) that the conduction in KDP is mainly due to the anions viz. $\left(\mathrm{H}_{2} \mathrm{PO}_{4}\right)^{-1}$ ions and not the cations viz. $\mathrm{K}^{+}$ions.

The $E$ values (see table 1 ) increase with the increase in impurity concentration in the case of $\left(\mathrm{NH}_{4}\right)_{2} \mathrm{CO}_{3}$ and $\mathrm{NH}_{4} \mathrm{Cl}$ impurities along both the $a$ - and $c$-directions $(E$ value for $\mathrm{NH}_{4} \mathrm{Cl}$ added KDP in 0.2 mole\% is slightly less than that for pure KDP along the $c$-direction). In the case of $\mathrm{NH}_{4} \mathrm{NO}_{3}$ and $\left(\mathrm{NH}_{4}\right)_{2} \mathrm{SO}_{4}$, the $E$ values along the $a$ direction decrease with the increase in impurity concentration. The $E$ values increase with the increase in impurity concentration along the $c$-direction in the case of $\left(\mathrm{NH}_{4}\right)_{2} \mathrm{SO}_{4}$ impurity. However, there is no systematic variation observed in the case of $\mathrm{NH}_{4} \mathrm{NO}_{3}$ (in the $c$ direction) and $\mathrm{NH}_{4} \mathrm{H}_{2} \mathrm{PO}_{4}$ (in both the $a$ - and $c$-directions) impurities.

\section{Conclusions}

Pure and impurity added (with five ammonium compounds separately) KDP single crystals were grown and conductivities were measured along both the $a$ - and $c$ - directions at various temperatures ranging from 28 to $140^{\circ} \mathrm{C}$. Density measurement indicates that the impurities have entered into the lattice of KDP crystals. Also, the present study gives further evidence to prove that the conduction in KDP is mainly due to the anions and not the cations. The present study indicates that the conductivity increases with the increase in impurity concentration and temperature. At low temperatures, the conductivities are more along the $a$-direction than those along the $c$ direction.

\section{References}

Bunget I and Popescu M 1984 Physics of solid dielectrics (New York: Elsevier)

Dean J A (ed.) 1979 Lange's handbook of chemistry (New York: Mc Graw Hill Book Company) 12 edn

George A W 1989 Nucl. Instrum. Meth. Phys. Res. B39 708

Granicher H, Jaccard C, Scherrer P and Steinemann A 1957 Discuss. Farad. Soc. 2350

Harris L B and Vella G J 1966 J. Appl. Chem. 17151

Henisch H K 1988 Crystals in gels and Liesegang rings (Cambridge: Cambridge University Press)

Jaccard C 1959 Helv. Phys. Acta 3289

Jain S C and Dahake S L 1964 Indian J. Pure \& Appl. Phys. 2 71

Keeffe M O' and Perrino C T 1967 J. Phys. \& Chem. Solids 28 211

Ramasubramanian P S and Mahadevan C 1991 Indian J. Pure \& Appl. Phys. 29285

Rashkovich L N 1991 KDP family single crystals (New York: Adam Hilger)

Shanmugham M, Gnanam F D and Ramasamy P 1982 Indian J. Pure \& Appl. Phys. 20579

Shanmugham M, Gnanam F D and Ramasamy P 1985 Indian J. Pure \& Appl. Phys. 2382

Subbarao E C 1973 Ferroelectrics 5267

Udupa K S, Mohan Rao P, Sriramana Aithal, Bhat A P and Avasthi D K 1997 Bull. Mater. Sci. 201069

Varma K B R, Ramanaiah K V and Rao K V 1983 Bull. Mater. Sci. 539

Wyckoff R W G 1960 Crystal structures (New York: Interscience) Vol. 3, II edn p.160 